\title{
Efeitos da suplementação com zinco sobre o crescimento, sistema imunológico e diabetes
}

\author{
Zinc supplementation and its effects on growth, \\ immune system, and diabetes
}

Karine Cavalcanti Maurício de SENA

Lucia de Fátima Campos PEDROSA

\section{R E S U M O}

O zinco apresenta funções catalíticas, estruturais e reguladoras, sendo componente de várias enzimas. Os sintomas observados na deficiência deste elemento incluem lesões de pele, anorexia, retardo do crescimento, hipogonadismo e alteração na função imune. O objetivo desta revisão foi apresentar as funções metabólicas e funcionais do zinco, enfatizando as conseqüências da deficiência e os aspectos que justificam os estudos envolvendo a suplementação com zinco e seus efeitos sobre o crescimento, sistema imunológico e diabetes. Considerando que algumas doenças predispõem o organismo à deficiência de zinco, a suplementação, isoladamente ou associada a outros elementos, demonstra benefícios, especialmente no aumento da velocidade de crescimento, funcionamento do sistema imunológico, diminuição das afecções respiratórias e controle das diarréias. A suplementação em pacientes com diabetes está relacionada com as variáveis do controle metabólico e as concentrações plasmáticas e eritrocitárias de zinco. As estratégias de suplementação com zinco, em populações de risco, devem ser implementadas, considerando-se as doses adequadas de ingestão.

Termos de indexação: crescimento, diabetes, sistema imunológico, suplementação, zinco.

\section{A B S T R A C T}

Zinc has catalytic, structural and regulatory functions and is a component of many enzymes. Skin lesions, anorexia, growth retardation, hypogonadism, immune suppression function are the symptoms caused by zinc deficiency. This review aims to present the structural and metabolic zinc functions, emphasising the consequences of zinc deficiency and the aspects that justify the studies on zinc supplementation, affecting growth, immune system and diabetes. Considering that some diseases predispose the organism to zinc deficiency, supplementation, either in isolation or in conjunction with other elements, demonstrates benefits, specifically in improved growth rate, immune system function, reduced respiratory infections and diarrhoea control. In diabetic patients, zinc supplementation has been associated with the variables in metabolic control and the concentrations of plasma and erythrocyte zinc. In populations at risk, Zinc supplementation strategies should be implemented, taking into consideration the adequacy of doses intake.

Indexing terms: growth, diabetes, immune system, supplementation, zinc.

\footnotetext{
1 Departamento de Nutrição, Universidade Federal do Rio Grande do Norte. Rua Gustavo Cordeiro de Farias, s/n, Petrópolis, 59010-180, Natal, RN, Brasil. Correspondência para/Correspondence to: K.C.M. SENA. E-mail: <kcmsena@ufrnet.br>.
} 


\section{N T R O D U Ç Ã O}

As funções bioquímicas do zinco podem ser refletidas pelo seu envolvimento na atividade de mais de 300 enzimas ${ }^{1}$. Apesar das baixas concentrações de zinco na maioria dos órgãos, as metaloenzimas dependentes deste mineral estão distribuídas em todos os tecidos do organismo, desempenhando processos fisiológicos importantes. Dentre as principais funções do zinco, destacam-se a participação na síntese e degradação dos carboidratos, lipídeos e proteínas, na manutenção do crescimento e do desenvolvimento normais, no funcionamento adequado do sistema imunológico, na defesa antioxidante, na função neurosensorial, e, também, na transcrição e tradução de polinucleotídios².

Nos últimos anos, a deficiência de zinco tornou-se um problema nutricional presente em países desenvolvidos ou em desenvolvimento. Esta abrange inúmeras anormalidades no metabolismo, tendo como causas a ingestão dietética inadequada, diminuição na absorção ou aumento na excreção urinária, presença de agentes na dieta que comprometem sua absorção, cirurgias do intestino, síndromes de má-absorção, doenças renais, doença crônica do fígado, abuso do álcool, nutrição parenteral total sem adição de zinco e, ainda, problemas genéticos ${ }^{3}$. Além de outras manifestações clínicas da deficiência deste mineral, ressaltam-se o retardo no crescimento, hipogonadismo, alteração da resposta imune, dificuldade de cicatrização, aumento do risco de aborto, diarréia, anorexia, perda de peso, alopécia, e a prematuridade na gestação².

Os parâmetros mais utilizados para avaliação do estado nutricional relativo ao zinco e, conseqüentemente, detecção de sua deficiência, são as medidas deste mineral no plasma, em componentes celulares do sangue (eritrócitos, monócitos, plaquetas, neutrófilos), no cabelo (a atividade de enzimas dependentes de zinco), bem como na excreção urinária. Normalmente, e utilizado mais de um biomarcador para avaliação do zinco no organismo, devido às baixas concentrações nos tecidos, e ao efetivo mecanismo homeostático para manutenção das concentrações plasmáticas e teciduais ${ }^{4}$.

Os produtos animais são geralmente as fontes dietéticas mais importantes de zinco, em termos de conteúdo e biodisponibilidade. Alguns fatores dietéticos, intralumiais e sistêmicos influenciam a captação e o transporte celular de zinco, tais como: forma química do elemento na dieta, interação mineral-mineral, taninos, oxalatos, fitatos, drogas, catabolismo, hormônios, infecções e estresse. As populações que têm como a base da dieta os alimentos de origem vegetal são predispostas à deficiência de zinco, devido, principalmente, à qualidade protéica e à alta ingestão de inositol hexafosfato (fitato) ${ }^{5}$. Baseada na relação entre os fatores da dieta e a biodisponibilidade de zinco, a Food and Agriculture Organization e a World Health Organization estabeleceram critérios de classificação das dietas de populações, quanto à biodisponibilidade de zinco, em alta, moderada e baixa, levando em consideração a presença na dieta de fitato, proteínas de origem animal e a razão molar fitato: zinco. Os estudos realizados em humanos demonstram que os fitatos apresentam uma potente capacidade de ligação com cátions divalentes, podendo prejudicar a absorção de zinco. No entanto, o efeito do fitato pode ser modificado a partir da fonte e da quantidade de proteínas consumidas na dieta. As proteínas de origem animal, por exemplo, parecem neutralizar o efeito inibitório do fitato na absorção de zinco, atribuindo-se isto, possivelmente, aos aminoácidos liberados da fração protéica do alimento, responsáveis pela manutenção do zinco em solução ${ }^{5}$.

Considerando-se a essencialidade do zinco, os suplementos dietéticos poderiam apresentar-se como uma estratégia para melhorar o cuidado à saúde em grupos populacionais susceptíveis à deficiência. Para tanto, é extremamente importante o conhecimento do limite superior tolerável de ingestão (Tolerable Upper Intake Level - UL), no sentido de direcionar os 
profissionais de saúde no desenvolvimento de programas com suplementação de zinco. Os valores dos UL enfocam os riscos de um excesso na ingestão inadequada de nutrientes e são estabelecidos a partir de evidências qualitativas e quantitativas em estudos que avaliam a associação entre a ingestão de nutrientes e a probabilidade de efeitos adversos. Portanto, o UL é determinado a partir da avaliação dos níveis de ingestão, elegendo-se aquele nível em que não se observa nenhum efeito adverso, ou o nível mais baixo de ingestão que não esteja associado a efeitos negativos. Este valor compreende a ingestão do nutriente proveniente dos alimentos que constituem a dieta, uso de suplementos e água. As principais conseqüências associadas à ingestão excessiva de suplementos de zinco incluem a supressão da resposta imune, a diminuição da lipoproteína de alta densidade (HDL) e a redução das concentrações de cobre plasmáticas ${ }^{6}$.

A suplementação com zinco, isolada ou juntamente com outros nutrientes, tem mostrado efeitos benéficos, principalmente em situações de dietas com baixa quantidade de produtos de origem animal ou de altas quantidades de fitatos, em crianças com retardo acentuado na velocidade de crescimento ou episódios de diarréia persistente, e ainda em pessoas com baixas concentrações plasmáticas de zinco ${ }^{7}$.

Embora sejam bastante discutidos os aspectos metabólicos do zinco, intrinsecamente associados com a fisiopatologia e controle do diabetes mellitus, verifica-se uma escassez de dados e de estudos envolvendo a suplementação deste mineral neste grupo de pacientes. A maioria dos artigos se refere ao efeito da suplementação do mineral na velocidade de crescimento, no controle de diarréias e de infecções respiratórias.

Algumas considerações importantes para a decisão sobre a melhor forma para oferecer os suplementos com zinco, são, por exemplo, a solubilidade, biodisponibilidade, sabor, efeitos colaterais, custo e freqüência da dose necessária ${ }^{7}$. As formas de zinco comumente usadas como suplementos nutricionais, ou na fortificação de alimentos, são o óxido e o sulfato de zinco, porém ambos apresentam desvantagens. O sulfato de zinco tem uma solubilidade adequada, mas interage com a matriz do alimento, modificando características sensoriais, tornando-o inaceitável. O óxido de zinco, por sua vez, não apresenta este efeito, por ser insolúvel e se precipitar em alimentos líquidos, limitando o seu uso a alimentos sólidos. O gluconato de zinco estabilizado com glicina, em soluções aquosas, tem demonstrado biodisponibilidade semelhante ao sulfato de zinco. Além desta vantagem, este produto não altera o sabor dos alimentos, sendo ainda considerado de baixo custo ${ }^{2}$.

A seguir, apresentam-se os resultados de trabalhos envolvendo a suplementação com zinco, destacando-se o impacto desta prática durante o crescimento e o desenvolvimento, no sistema imunológico e no diabetes mellitus.

\section{E FEITOS D A S U P LEMENTAÇÃ O COM ZINCO NO CRESCIMENTO}

O crescimento ocorre por meio da divisão celular e requer DNA, RNA e síntese protéica. O zinco participa de uma variedade de processos celulares como um co-fator para inúmeras enzimas, influenciando a expressão gênica por meio de fatores de transcrição. Numerosas enzimas associadas à síntese de DNA e RNA são metaloenzimas dependentes de zinco, incluindo a RNA polimerase, transcriptase reversa e fator de transcrição IIIA. Nestas enzimas, o zinco está firmemente ligado, estabilizando estruturas que são funcionalmente importantes. Por outro lado, o zinco também pode influenciar a regulação hormonal da divisão celular, especialmente via hormônio do crescimento $(\mathrm{GH})$ e fator I do crescimento dependente de insulina (IGF-I), além de interferir em hormônios mitogênicos, atuando sobre a proliferação celular .

Ghavami-Maibodi et al. ${ }^{9}$ acompanharam dois grupos de crianças com baixa velocidade de crescimento, suplementadas com doses variadas 
de zinco: um, com 50mg/Zn/dia por dois meses e, subseqüentemente, $50 \mathrm{mg} / \mathrm{Zn} /$ dia uma vez por semana por dez meses; outro, com 100mg/Zn/ dia por um ano. Evidenciaram um aumento estatisticamente significativo tanto na taxa de crescimento, como nas concentrações de zinco no cabelo, soro e urina, de ambos os grupos, embora os efeitos fossem mais pronunciados no grupo suplementado com a dose maior. Neste, após um ano de suplementação com 100mg de zinco, houve redução significativa nos níveis de cobre, não se observando o mesmo efeito no grupo que recebeu dose menor.

Nakamura et al. ${ }^{10}$ desenvolveram um estudo com dez crianças com deficiência leve e moderada de zinco que apresentavam baixa estatura. As crianças receberam $5 \mathrm{mg} / \mathrm{kg} / \mathrm{dia}$ de sulfato de zinco por um período de seis meses. Durante o estudo, foi observado aumento significativo nas concentrações de zinco, cálcio e fósforo no soro. Verificou-se ainda que a excreção urinária do hormônio do crescimento não foi modificada no grupo experimental. Os autores concluíram que a suplementação com zinco é efetiva para induzir o crescimento em crianças que apresentam deficiência do metal e baixa estatura. Outro aspecto verificado foi que o teste de "clearance" de zinco corporal facilita a detecção da deficiência moderada de zinco.

Considerando a importância do zinco no crescimento e a elevada prevalência da deficiência deste mineral, Brown et al. ${ }^{11}$ conduziram uma investigação de meta-análise para avaliar os estudos publicados entre 1969 e 1996, sobre suplementação com zinco, relacionada com as variações de peso e estatura em crianças com idade inferior a 13 anos. As doses usadas para a suplementação variaram de 1,5 a 50mg/dia (média de $14 \mathrm{mg} / \mathrm{dia}$ ), ou com a freqüência de 5 a 6 dias por semana. Os resultados demonstraram um impacto pequeno, porém significativo, da suplementação com zinco no aumento do peso e na velocidade de crescimento. Tal análise reforçou a importância da implementação de programas de suplementação com zinco em populações de crianças com baixa estatura e/ou com deficiência de zinco no plasma.

Estudo desenvolvido por Kikafunda et al. ${ }^{12}$ revelou que seis meses de suplementação com $10 \mathrm{mg}$ zinco/dia foram suficientes para melhorar o estado nutricional de crianças desnutridas e de baixas condições socioeconômicas. O efeito positivo do zinco no aumento do crescimento linear em crianças com déficit de estatura também foi evidenciado na zona rural da Guatemala por Rivera et al. ${ }^{13}$.

Os trabalhos apontam para o fato de a suplementação com zinco apresentar benefícios sobre o crescimento em diferentes estágios de vida. Um aumento na velocidade de crescimento foi observado em pré-adolescentes e adolescentes com baixa estatura, após suplementação com zinco (10mg Zn/dia, por um período de doze meses), independente do sexo ${ }^{14}$. Bebês com $29 \pm 2,9$ semanas e baixo peso ao nascer, suplementados com $11 \mathrm{mg} \mathrm{Zn} / \mathrm{L}$ de fórmula durante seis meses, apresentaram aumento na concentração de zinco plasmático, maior velocidade de crescimento linear e ainda, pontuação máxima no desenvolvimento motor ${ }^{15}$.

\section{EFEITOS DASUPLEMENTAÇÃ O COM ZINCO SOBREO SISTEMAIMUNOLÓ GICO}

No sistema imunológico o zinco desempenha papel fundamental, pelo fato de as células do sistema imune apresentarem altas taxas de proliferação, e este mineral estar envolvido na tradução, transporte e replicação do DNA. O zinco pode, ainda, afetar o processo de fagocitose dos macrófagos e neutrófilos, interferir na lise celular mediada por células natural killer e ação citolítica das células T. A influência direta do zinco no sistema imune acontece devido a este elemento estimular a atividade de enzimas envolvidas no processo de mitose, como a DNA e a RNA polimerase, timidina quinase, desoxiribonucleotidol terminal transferase e ornitina descarboxilase. A deficiência de zinco está relacionada com a atrofia 
do timo, assim como de outros órgãos linfóides e a linfocitopenia em animais e humanos. Evidências experimentais demonstram diminuição na razão CD4:CD8, durante a deficiência de zinco, além da diminuição de precursores de linfócitos-T citotóxicos. A modificação nas proporções de linfócitos pode contribuir para o desequilíbrio do sistema imunológico, afetando sua resposta e sua regulação ${ }^{16}$.

A deficiência moderada de zinco, notadamente em pacientes com anemia falciforme, doença renal, doenças gastrintestinais crônicas, acrodermatite enteropática, pacientes com AIDS e crianças com diarréia, pode alterar os sistemas de defesa, favorecendo o aumento de infecções oportunistas e, conseqüentemente, da taxa de mortalidade. Curtos períodos de suplementação podem melhorar a defesa imune de pacientes com estas doenças ${ }^{17}$.

Sazawal et al. ${ }^{18}$ relataram que a suplementação com zinco favoreceu o aumento das células CD3, CD4, razão CD4/CD8, sem nenhuma diferença em CD8 e CD20 - aumento que possivelmente explica o efeito do zinco no controle da diarréia e das infecções respiratórias em crianças pré-escolares.

Os efeitos da suplementação com zinco sobre o sistema imunológico de adultos portadores de anemia falciforme foram objeto do estudo realizado por Prasad et al. ${ }^{19}$. Para tanto, 32 pacientes receberam, via oral, uma suplementação com acetato de zinco (50 a 75mg/dia de zinco elementar) durante dois ou três anos. A administração prolongada de zinco provocou um aumento do zinco nos leucócitos, granulócitos e na produção de IL-2, diminuição da incidência de infecções causadas por bactérias e do número de crises associadas a dores vaso-oclusivas, bem como um decréscimo no número de internações.

Estudos sobre suplementação com zinco em pacientes portadores do vírus da imunodeficiência humana (HIV) têm sido conduzidos em adultos e crianças, porém os resultados não são conclusivos. Os dados disponíveis sobre o envolvimento do zinco na imunidade sugerem que a deficiência deste mineral pode aumentar a replicação do HIV, prejudicar a imunidade celular e acelerar a apoptose das células envolvidas na resposta imune. No entanto, Coovadia \& Bobat ${ }^{20}$ não confirmam estas afirmações ao observarem que as crianças infectadas por HIV não apresentam deficiência significante de zinco, nem qualquer associação entre a progressão da doença e as concentrações de zinco, além de não obterem benefícios significativos da suplementação com o mineral. Quanto aos adultos soropositivos observados, apresentam efeitos inconsistentes da deficiência, incluindo, entretanto, uma maior resistência do HIV, menor número de CD4 e maior mortalidade. Segundo os autores, não existem dados suficientes para afirmar que a suplementação de zinco pode melhorar a saúde e a progressão da doença em adultos e crianças infectadas pelo HIV.

O impacto da suplementação de zinco em 32 crianças que apresentavam desnutrição energético-protéica foi estudado por Chevalier et al. ${ }^{21}$. As crianças desnutridas, com idade média de 18,8 \pm 7,2 meses, receberam $2 \mathrm{mg} / \mathrm{Zn} / \mathrm{Kg} /$ dia durante dois meses, como tratamento para estimular o sistema imunológico e acelerar a reabilitação imunológica destas crianças. Foi constituído um grupo controle sem suplementação, composto por crianças desnutridas de características semelhantes às das suplementadas. Os resultados evidenciaram que as crianças tratadas com o suplemento diário de zinco tiveram uma recuperação mais rápida da massa tímica, quando comparadas às do grupo controle, e alcançaram a recuperação do sistema imunológico em um mês. Para as crianças do grupo-controle, que não receberam suplemento de zinco, foram necessários dois meses para que se observassem tais recuperações.

\section{EFEITO DA SUPLEMENTAÇÃ O COM ZINCO EM PACIENTES COM DIABETES MELLITUS}

A relação zinco-diabetes pode ser atribuída, principalmente, ao estímulo à secreção, estoca- 
gem de insulina e metabolismo da glicose. Adicionalmente, em pacientes com diabetes evidencia-se o risco aumentado para a deficiência de zinco, atribuído, geralmente, às perdas do mineral na urina, diminuição na capacidade intestinal de absorção de zinco, além da baixa ingestão dietética. Pelo fato destes pacientes constituírem população de risco para desenvolver a deficiência de zinco, os estudos apontam a necessidade de suplementação deste mineral. No entanto, é importante estar atento para que o suplemento de zinco não venha a prejudicar, interferindo no metabolismo da glicose e no tratamento primário dos pacientes envolvidos ${ }^{22}$.

Os parâmetros bioquímicos mais utilizados para a avaliação de zinco nestes pacientes têm sido as medidas deste no plasma, soro e urina, ou ainda, em menor proporção, nos eritrócitos, nos leucócitos, e nas plaquetas e células do sistema imune. De uma maneira geral, os resultados desses estudos são interpretados considerando-se o tempo de duração da doença, o controle metabólico e as complicações, quando existentes ${ }^{22}$.

Cunningham et al. ${ }^{23}$ conduziram um trabalho cujo objetivo foi investigar a influência da suplementação do zinco sobre os parâmetros de avaliação do mineral no plasma, células sangüíneas e excreção urinária. Os pacientes com diabetes tipo $1(n=6)$ e pessoas saudáveis $(n=7)$ receberam $50 \mathrm{mg} /$ dia de zinco, diariamente, durante 28 dias. O grupo diabetes tipo 1 demonstrou acentuado incremento na hiperzincúria após a suplementação, observando-se ainda, excreção aumentada de zinco nas pessoas saudáveis. As concentrações de zinco nos leucócitos, em ambos os grupos, apresentaram-se aumentadas, embora os baixos teores de zinco nos eritrócitos de pacientes com diabetes tipo 1 persistissem durante o tratamento. Foi verificado também um aumento da hemoglobina glicada, sugerindo um efeito adverso diante da ingestão de altas doses de zinco, embora não se tenham elucidado os mecanismos envolvidos.

Sena \& Pedrosa ${ }^{24}$ acompanharam 20 crianças com diabetes tipo 1, atendidas no
Ambulatório de Endocrinologia Pediátrica da Universidade Federal do Rio Grande do Norte - Natal, $\mathrm{RN}$, e evidenciaram que a suplementação de zinco favoreceu o aumento dos teores de zinco eritrocitários na maioria dos pacientes e, por outro lado, a diminuição das concentrações plasmáticas elevadas constatadas em alguns pacientes antes da suplementação. O uso da suplementação não influenciou na zincúria, característica marcante destes pacientes. Quanto às variáveis do controle metabólico, foi constatado um discreto aumento, porém significativo, das concentrações de hemoglobina glicada após a administração do suplemento. Os autores especularam quanto às outras variáveis que possam ter influenciado neste resultado como, por exemplo, o aumento do apetite observado nos pacientes.

Em pacientes diabéticos com complicações, observou-se que os valores basais de zinco no plasma eram menores naqueles com retinopatia; tais valores melhoraram significativamente após a suplementação com uma dose diária de $30 \mathrm{mg} / \mathrm{dia}$, durante três meses. O efeito antioxidante do zinco foi evidenciado pelo aumento da atividade da glutationa peroxidase e pela redução de substâncias indicadoras da peroxidação lipídica ${ }^{25}$.

Rausher et al. ${ }^{26}$ avaliaram o envolvimento da suplementação de zinco em pacientes com diabetes tipo 2, usando a técnica de isótopos marcados, monitorados nas fezes. No entanto, não foi possível estabelecer conclusões a respeito da relação do diabetes tipo 2 com a absorção e excreção de zinco, pelo fato de terem sido observadas diferenças nos pools de zinco permutáveis.

Outro importante aspecto investigado refere-se à influência do zinco na prevenção do diabetes mellitus. Tobia et al. ${ }^{27}$ constataram que o zinco pode ser efetivo na prevenção do início do diabetes mellitus em ratos BB Wistar propensos a desenvolver diabetes. A suplementação de 1000 ppm de zinco nestes animais resultou em uma menor incidência de diabetes, se comparados a animais que não foram suplementados ou com 
os que receberam $50 \mathrm{ppm}$ de zinco. Posteriormente, Ho et al. ${ }^{28}$ observaram, em camundongos suplementados com zinco, uma inibição na ativação do NFאB (um fator de transcrição, regulador da resposta imunológica e sensível a espécies reativas de oxigênio), o que, conseqüentemente, protegeu as células $\beta$ pancreáticas contra a destruição.

Simon \& Taylor ${ }^{29}$, em modelo experimental com camundongos $\mathrm{db} / \mathrm{db}$, fizeram um estudo comparativo entre uma dieta deficiente em zinco ( $3 p p m$ Zn/dia) e outra suplementada (300ppm Zn/dia), com o controle glicêmico dos animais. A dieta padrão adequada continha 30ppm Zn/dia. Os camundongos suplementados apresentaram diminuição da glicemia de jejum, assim como baixas concentrações de insulina plasmática e maiores teores de zinco pancreáticos, diferente do que foi observado no grupo com dieta deficiente. Os autores especularam sobre um possível envolvimento do zinco no controle glicêmico, mediado por efeitos nas células $\beta$ pancreáticas e mecanismos de ação da insulina.

Estudar a associação de suplemento de zinco com outros minerais em pacientes com diabetes tipo 2 foi objetivo de um trabalho conduzido por Anderson et al. ${ }^{30}$. Adultos com hemoglobina glicada $>7,5 \%$, distribuídos em quatro grupos, foram suplementados por um período de seis meses: cada grupo recebeu, respectivamente: $30 \mathrm{mg} / \mathrm{dia}$ de zinco na forma de gluconato de zinco; $400 \mu \mathrm{g} /$ dia de cromo (picolinato de cromo); suplementação combinada de zinco+cromo; e placebo. Os resultados revelaram diminuição significativa nas concentrações plasmáticas das substâncias reativas do ácido tiobarbitúrico nos três grupos suplementados - com cromo, com zinco, e com zinco+cromo. O mesmo não foi observado nos pacientes que receberam placebo. Não foi verificada diferença estatisticamente significante entre os grupos suplementados com minerais, quando estes foram analisados separadamente. A suplementação não modificou em nenhum dos grupos, os valores de hemoglobina glicada, nem a homeostase da glicose, não se verificando ainda nenhum efeito adverso sobre as concentrações plasmáticas de cobre, HDL-colesterol ou interações zinco/cromo.

\section{O N C L US Ã O}

A suplementação de zinco pode apresentar efeitos positivos em situações clínicas de caráter agudo ou crônico, abrangendo crianças, jovens, adultos e idosos. Segundo a maioria dos estudos, esta prática, adotada para crianças e adolescentes com deficiência de crescimento, em faixas etárias variadas, apresenta resultados positivos sobre a velocidade de crescimento. Entretanto, na maioria dos trabalhos observa-se uma falta de padronização quanto à determinação das doses utilizadas, bem como a especificação do tempo necessário para verificar a melhora do crescimento frente à suplementação do zinco.

O efeito da suplementação de zinco sobre o sistema imunológico apresenta melhores resultados em crianças, aumentando o controle de diarréias e infecções respiratórias, bem como favorecendo uma rápida recuperação das funções do sistema imune em crianças com desnutrição energético-protéica. Em adultos, os benefícios são evidentes em pacientes com anemia falciforme, constatando-se uma maior resistência às infecções por bactérias. Quanto aos pacientes infectados por HIV, os estudos com suplementação de zinco não são conclusivos, sugerindo a necessidade de pesquisas adicionais.

Em estudo de diabetes experimental em animais, os efeitos benéficos da suplementação de zinco são evidenciados pela melhora do controle glicêmico e da homeostase da glicose, e pela prevenção do surgimento do diabetes. No entanto, os resultados em humanos são controversos, observando-se desde a melhora do estado nutricional relativo ao zinco no organismo, até a alteração no controle glicêmico quando são utilizadas doses elevadas do mineral. As limitações para o alcance de consensos, nesses estudos, devem-se à dificuldade em controlar outras variáveis, as quais podem interferir no controle metabólico da doença. 
Considerando os resultados encontrados, sugere-se a necessidade de pesquisas complementares, a fim de se procederem às recomendações específicas deste mineral para portadores de doenças crônicas - os quais, provavelmente, necessitem de uma ingestão de zinco diferenciada em relação à população saudável.

Os resultados destas pesquisas alertam para a necessidade de aplicação de estratégias de suplementação com zinco, como conduta nutricional preventiva e/ou corretiva da deficiência deste mineral em populações de risco. Para tanto, ressalta-se a importância de padronizações das quantidades de zinco administradas, levando em conta tanto as necessidades de zinco, que variam segundo o sexo, estágio de vida e estado de saúde ou doença, quanto os níveis de ingestão máxima permitida desse mineral.

\section{REFERÊ NCIAS}

1. McCall KA, Huang CC, Fierke CA. Function and mechanism of zinc metalloenzymes. J Nutr. 2000; 130(5):1437S-46.

2. Salgueiro MJ, et al. Zinc as an essencial micronutrient: a review. Nutr Res. 2000; 20(5): 737-55.

3. Prasad AS. Zinc deficiency in women, infants and children. J Am Coll Nutr. 1996; 15(2):113-20.

4. Hambidge, M. Biomarkers of trace mineral intake status. J Nutr. 2003; 133(3 Suppl):948S-55.

5. Food and Agriculture Organization. World Health Organization. Human vitamin and mineral requirements. Report of a joint FAONHO expert consultation. Bangkok; 2002. p. 257-70.

6. National Academy of Sciences, Food and Nutrition Board, Institute of Medicine (USA) - Dietary Reference Intakes (DRI) for vitamin A, vitamin K, Arsenic, Boron, Chromium, Cooper, lodine, Iron, Manganese, Molybdenum, Nickel, Silicon, Vanadium and Zinc. Washington, DC.; 2001. 650p.

7. Allen LH. Zinc and micronutrient supplements for children. Am J Clin Nutr. 1998; 68(2):485S.

8. MacDonald RS. The role of zinc in growth and cell proliferation. J Nutr. 2000; 130(5):1500S-8S.

9. Ghavami-Maibodi SZ, Collip PJ, Castro-Magana M, Stewart C, Chen SY. Effect of oral zinc supplements on growth, hormonal levels, and zinc in healthy short children. Ann Nutr Metabol. 1983; 27(3):214-9.

10. Nakamura T, Nishiyama S, Futagoishi-Suginohara Y, Matsuda I, Higashi A. Mild to moderate zinc deficiency in short children: effect of zinc supplementation on linear-growth velocity. J Pediatr. 1993; 123(1):65-9.

11. Brown KH, Peerson JM, Allen LH. Effect of zinc supplementation on children's growth: A meta-analysis of intervention trials. Bibl Nutr Dieta. 1998; 54(1):76-83.

12. Kikafunda JK, Walker AF, Allan EF, Tumwine JK. Effect of zinc supplementation on growth and body composition of Ugandan preschool children: a randomized controlled, intervention trial. Am J Clin Nutr. 1999; 70(1):110-3.

13. Rivera JA, Ruel MT, Santizo MC, Lönnerdal B, Brown $\mathrm{KH}$. Zinc supplementation improves the growth of stunted rural Guatemalan infants. J Nutr. 1998; 128(3):556-62.

14. Castillo-Duran C, Garcia H, Venegas P, Torrealba I, Panteon E, Concha N, et al. Zinc supplementation in very-slow-growth velocity of male children adolescents with short stature. Acta Pediatric. 1994; 83(8):833.

15. Friel JK, Andrews WL, Matthew JD, Long DR, Cornel AM, Cox M, et al. Zinc supplementation in very-low-birth-weight infants. J Pediatr Gastroenterol Nutr. 1993; 17(1):97-103.

16. Salgueiro MJ, Zubillaga MB, Lysionek AE, Sarabia MI, Caro RA, De Paoli T, et al. Zinc status and immune system relationship: A review. Biol Trace Elem Res. 2000; 76(3):193-205.

17. Fraker PJ, King LE, Laakko T, Vollmer TL. The dynamic link between the integrity of the immune system and zinc status. J Nutr. 2000; 130(5 Suppl): $13995-406$.

18. Sazawal S, Jalla S, Mazumder S, Sinha A, Black RE, Bahan MK. Effect of zinc supplementation on cell-mediated immunity and lymphocyte subjects in preschool children. Indian Pediatr. 1997; 37(7): 589-97.

19. Prasad AS, Beck FW, Kaplan J, Chandrasekar PH, Ortega J, Fitzgerald JT, et al. Effect of zinc supplementation on incidence of infections and hospital admissions in sickle cell disease (SCD). Am J Hematol. 1999; 61(3):194-202.

20. Coovadia HM, Bobat R. Zinc deficiency and supplementation in HIV/AIDS. Nutr Res. 2002; 22(1-2):179-91.

21. Chevalier P, Sevilla R, Zalles L, Sejas E. Effect of zinc supplementation on nutritional immune deficiency. Nutr Res. 1994; 16(3):369-79. 
22. Salgueiro MJ, Krebs N, Zubillaga MB, Weill R, Postaire $E$, Lysionek $A E$, et al. Zinc and diabetes mellitus: is there a need of zinc supplementation in diabetes mellitus patientes? Biol Trace Elem Res. 2001; 81(3):215-28.

23. Cunningham JJ, Fu A, Mearkle L, Brown G. Hiperzincuria in individuals with Insulin-Dependent Diabetes mellitus: concurrent zinc status and effect of high-dose zinc supplementation. Metabolism. 1994; 43(12): 1558-62.

24. Sena KCM, Pedrosa LFC. Efeito da suplementação oral de zinco em crianças e adolescentes com diabetes tipo 1 [dissertação]. Natal: Universidade Federal do Rio Grande do Norte; 2002.

25. Faure P, Benhamou PY, Perard A, Halimi S, Roussel AM. Lipid peroxidation in insulin-dependent diabetic patients with early retina degenerative lesions: effects of an oral zinc supplementation. Eur J Clin Nutr. 1995; 49(4):282-8.

26. Rauscher AM, Fairweather-Tait SJ, Wilson PD, Gorrick WS, Greenwood R. Zinc metabolism in non-insulin dependent diabetes mellitus. J Trace Elem Med Biol. 1997; 11(2):65-70.
27. Tobia MH, Zalanowicz MM, Wingertzahn MA, McHeffey-Atkinson B, Slovim AE, et al. The role of dietary zinc in modifying the onset and severity of spontaneous diabetes in the BB Wistar rat. Mol Gen Metabol. 1998; 63(3):205-13.

28. Ho E, Quan N, Tsai YH, Lai W, Bray TM. Dietary zinc supplementation inhibits NFKB activation and protects against chemically induced diabetes in CD1 mice. Proc Soc Exp Biol Med. 2001; 226(2):103-11.

29. Simon SF, Taylor CG. Dietary zinc supplementation attenuates hyperglycemia in $\mathrm{db} / \mathrm{db}$ mice. Proc $\mathrm{Soc}$ Exp Biol Med. 2001; 226(1):43-51.

30. Anderson RA, Roussel AM, Zouari N, Mahjoub S, Matheu JM, Kerkeni A. Potencial antioxidant effects of zinc and chromium supplementation in people with type 2 diabetes mellitus. J Am Coll Nutr. 2001; 20(3):212-18.

Recebido para publicação em 31 de outubro de 2002 e aceito em 24 de novembro de 2003. 